\title{
Contribution of prosthetic treatment considerations for dental extractions of permanent teeth
}

Miguel Ángel Fernández-Barrera, Carlo Eduardo Medina-Solís, Juan Fernando Casanova-Rosado, Martha Mendoza-Rodríguez, Mauricio Escoffié-Ramírez, Alejandro José Casanova-Rosado, José de Jesús Navarrete-Hernández, Gerardo Maupomé

Background: Tooth loss is an easily identifiable outcome that summarizes a complex suite of factors in an individual's history of dental disease and its treatment by dental services over a lifetime. Assessment of overall tooth loss data is essential for evaluating epidemiologically the adequacy of dental care provided at a systems level, as well as for placing in context tooth loss for non-disease causes. For example, when derived from prosthetic treatment planning; the latter may unfortunately lead to some teeth being extracted (pulled) for the sake of better comprehensive clinical results. The objective of the present manuscript was to identify the contribution to overall tooth loss, by extraction of permanent teeth because of prosthetic treatment reasons. Material and Methods: A cross-sectional study included sex, age, total number of extractions performed by subject, sextant (anterior vs. posterior), group of teeth (incisors, canines, premolars and molars), upper or lower arch, and the main reason underlying extraction (extraction for any reason vs. prosthetic treatment), in patients 18 years of age and older seeking care a dental school clinic in Mexico. A multivariate logistic regression model was generated. Results: A total of 749 teeth were extracted in 331 patients; 161 teeth ( $21.5 \%$ of total) were extracted for explicit prosthetic treatment indications. As age increased, the likelihood of having an extraction for prosthetic reasons increased $3 \%(O R=1.03, p<0.001)$. Women $(O R=1.57, p<0.05)$ were more likely to be in this situation, and molars $(O R=2.70$, $\mathrm{p}<0.001$ ) were most at risk. As the total number of extractions increased, the risk of having an extraction for prosthetic reasons decreased $(O R=0.94, p<0.05)$. Conclusions: $A$ significant amount $(21.5 \%)$ of the extractions of permanent teeth were performed for prosthetic reasons in this dental school clinical environment; age, sex, type of tooth, and the total number of extractions moderated such pattern. 


\section{5}

\author{
4 Short title: Prosthetic considerations to extract teeth
} . Casanova-Rosado, ${ }^{3}$ Rosado, $^{3}$ Hidalgo State. Pachuca, Mexico. Dentistry, Autonomous University State of Mexico. Toluca, México. IN, USA.

Correspondence:

\section{Contribution of dental prosthetic treatment considerations to the overall experience of permanent teeth extracted}

Miguel Ángel Fernández-Barrera, ${ }^{1}$ Carlo Eduardo Medina-Solís, ${ }^{1,2}$ Juan Fernando

Martha Mendoza-Rodríguez, ${ }^{1}$ Mauricio Escoffié-Ramírez, ${ }^{4}$ Alejandro José CasanovaJosé de Jesús Navarrete-Hernández, ${ }^{1}$ Gerardo Maupomé. ${ }^{5}$

${ }^{1}$ Academic Area of Dentistry of Health Sciences Institute at Autonomous University of

${ }^{2}$ Advanced Studies and Research Center in Dentistry "Dr. Keisaburo Miyata", School of

${ }^{3}$ School of Dentistry of Autonomous University of Campeche. Campeche, México. ${ }^{4}$ School of Dentistry of Autonomous University of Yucatan. Mérida, México.

${ }^{5}$ Indiana University / Purdue University at Indianapolis School of Dentistry. Indianapolis, 
23 MSc. Carlo Eduardo Medina Solís. Avenida del Álamo \# 204, Fraccionamiento Paseo

24 de los Solares. Colonia Santiago Tlapacoya. CP. 42110. Pachuca de Soto, Hidalgo,

25 México. email: cemedinas@yahoo.com 


\section{Abstract}

Background: Tooth loss is an easily identifiable outcome that summarizes a complex suite of factors in an individual's history of dental disease and its treatment by dental services over a lifetime. Assessment of overall tooth loss data is essential for evaluating epidemiologically the adequacy of dental care provided at a systems level, as well as for placing in context tooth loss for non-disease causes. For example, when derived from prosthetic treatment planning; the latter may unfortunately lead to some teeth being extracted (pulled) for the sake of better comprehensive clinical results. The objective of the present manuscript was to identify the contribution to overall tooth loss, by extraction of permanent teeth because of prosthetic treatment reasons. Material and Methods: A cross-sectional study included sex, age, total number of extractions performed by subject, sextant (anterior vs. posterior), group of teeth (incisors, canines, premolars and molars), upper or lower arch, and the main reason underlying extraction (extraction for any reason vs. prosthetic treatment), in patients 18 years of age and older seeking care a dental school clinic in Mexico. A multivariate logistic regression model was generated. Results: A total of 749 teeth were extracted in 331 patients; 161 teeth $(21.5 \%$ of total) were extracted for explicit prosthetic treatment indications. As age increased, the likelihood of having an extraction for prosthetic reasons increased $3 \%$ $(O R=1.03, p<0.001)$. Women $(O R=1.57, p<0.05)$ were more likely to be in this situation, and molars $(\mathrm{OR}=2.70, \mathrm{p}<0.001)$ were most at risk. As the total number of extractions increased, the risk of having an extraction for prosthetic reasons decreased $(\mathrm{OR}=0.94$, $p<0.05)$. Conclusions: A significant amount $(21.5 \%)$ of the extractions of permanent 
49 teeth were performed for prosthetic reasons in this dental school clinical environment;

50 age, sex, type of tooth, and the total number of extractions moderated such pattern.

51

52 Keywords: oral health; dental extraction; adults; pre-prosthetic treatment; Mexico. 


\section{Introduction}

54 According to Marcenes et al. (2014) and Kassebaum et al. (2014, 2015) oral conditions

55 have remained prevalent worldwide. Untreated caries (tooth decay) in permanent teeth

56 is the most prevalent condition as evaluated in the landmark "Global Burden of Disease

572010 Study", while severe periodontitis (gum disease), and untreated caries in

58 deciduous teeth were the 6th and 10th most prevalent conditions affecting $11 \%$ and $9 \%$

59 of the global population, respectively. Severe tooth loss was the 36 th most frequent

60 situation with a global estimate of $2 \%$. Dental caries manifests as a continuum of

61 disease states of increasing severity and tooth destruction. These can range from sub-

62 clinical, asymptomatic changes in tooth structure to carious lesions with extensive

63 pulpal involvement (Kassebaum et al., 2014). Moreover, periodontal diseases are

64 chronic disorders affecting the tissues supporting the teeth. Inflammatory events

65 associated with loss of connective tissue also lead to resorption of alveolar bone

66 support (Armitage et al., 2003; Greenwell et al., 2001). Caries and destructive

67 periodontal diseases are major oral public health problems and often quoted to be the

68 leading causes of permanent teeth extraction (pulling teeth) (Haseeb, Ali, \& Munir,

69 2012, Jafarian \& Etebarian, 2013, Saheeb \& Sede, 2013, Lee et al., 2015).

70 Tooth loss is a multifactorial and complex outcome that reflects diverse circumstances

71 of the individual's history of dental disease and its treatment with dental services over a

72 lifetime (Kassebaum et al., 2014b). Tooth loss has been proposed as a negative

73 indicator of oral health: various international oral health-related agencies have

established global oral health goals for the year 2020 (Hobdell et al., 2003) that include

75 preservation of dentition is one of the most important goals of preventive dentistry. 
76 Despite progress in technical procedures, tooth extraction is one of the most widely

77 performed procedures in dentistry today in many parts of the world (Lesolang, Motloba

data is essential for evaluating the adequacy of dental care services provided across diverse locations in the world, it remains just as important to place in context why tooth loss happens - in particular when prosthetic treatment planning inevitably implies selective tooth extraction. Simply put, some teeth are extracted for the greater good of the mouth through treatment planning of dental services despite the fact that their survival as an individual tooth could have taken place (Alomari, Khalaf, \& Al-Shawaf, 2013). Placing dental prostheses is a common dental course of treatment aiming to replace missing teeth; such rehabilitation of function and appearance may be attained using fixed or removable prostheses, partially replacing teeth or completely (full dentures). Treatment planning and management include diagnostic evaluation of whether teeth still in the mouth can be safely thought to be stable in their survival over time (therefore optimizing the likelihood of prostheses performing adequately), or if some of those teeth should be selectively eliminated and replaced through a prosthetic substitution. The guiding principle is that some teeth may need to be sacrificed for the sake of better prosthesis design or function. Factors often incorporated to this stage of treatment planning include location of tooth in dental arch, periodontal status, root-tocrown ratio of alveolar bone support, need for and likelihood of success of endodontic treatment, interocclusal relationship, and aesthetic condition and relative contribution to overall appearance (Davarpanah et al., 1998, Freitas et al., 2012). 
98 An accurate understanding of the relative contribution of prosthetic reasons to the

99 extraction of teeth ought to differentiate actual reasons leading to overall tooth loss

100 prevalence. Only a few reports in the world literature have made this distinction, and

101 suggested a wide range of prevalence for tooth extractions undertaken for prosthetic

102 reasons: from 23.2\% (Abreu et al., 1998) to 3.4\% (Rubiños et al., 2008). The objective

103 of the present study was to add to such body of literature, through quantifying the

104 contribution of prosthetic treatment planning as the reason for extracting permanent

105 teeth, taking into account demographic factors.

108 Material and Methods

Study location

110 A cross-sectional study was undertaken on the clinical records of patients seeking care

111 at dental school clinics of the Autonomous University of Hidalgo State (UAEH), in

112 Central Mexico. The dental health care system in Mexico is a mixed and fragmented

113 health system composed of public services and social security efforts supplied by public

114 institutions, third party payment systems, and private carriers. The overwhelming

115 majority of services are delivered under a fee-for-item, out-of-pocket scheme run by

116 largely unregulated dental professionals and dental market. The public health sector is

117 responsible for a small, essentially undetermined and largely fluid set of services that

118 are almost restricted to the urban settings. In contrast, dozens of dental school clinics in

119 numerous public and private universities offer dental services to the population,

120 provided by students under close faculty supervision, at much-reduced prices (Pérez et 
121 al., 2006, Minaya et al., 2015). While not an organized, distinct clinical care system,

122 services delivered in dental school clinics constitute a significant portion of dental care

123 services available to the open population.

\section{Design and study population}

125 Part of the methodology has been previously published (Medina et al., 2013, Medina et

126 al., 2014). No sampling was performed because we enrolled all consecutive patients

127 seen for uncomplicated tooth extractions in one calendar year (2009). Clinical

128 examinations, taking medical/dental histories, and periapical radiographs are routinely

129 performed on all patients scheduled for tooth extractions. The extractions incorporated

130 to the present study ( $\mathrm{n}=749$ in 331 patients) were performed under local anaesthesia by

131 senior dental students under the supervision of clinical faculty. Inclusion criteria were: a)

132 patients of either sex, b) 18 years of age or older, and c) with complete clinical data

133 available, as described above.

134 Variables

135 Independent variables included patient age, which was divided into three groups: 0=18-

13644 years of age, $1=45-59$ years, and $2=\geq 60$ years; sex: $0=$ men and $1=$ women; arches:

$1370=$ upper and $1=$ lower; sextant: $0=$ =anterior and $1=$ =posterior; type of tooth: $0=$ incisors,

1381 =canines, $2=$ =premolars, and 3=molars. The dependent variable was the reason why

139 the extraction was performed; it was coded as $0=$ any other clinical reason, or $1=$

140 extraction for prosthetic reasons. The latter was supported by analyses of dental casts

141 and radiographs evaluated by clinical faculty. Teeth scheduled for extraction for

142 prosthetic reasons may had also been carious or have periodontal problems; however,

143 categories for tooth extraction were based on the clinical notes and the treatment 
144 planning considerations entered. Even teeth that were seemingly healthy may have

145 been scheduled for extraction as a part of a treatment plan for a dental prosthesis

146 (fixed, removable, or full).

\section{Statistical analysis}

148

150

151

152

153

154

155

156

157

158

159

160

161

162

163

164

165

166

Statistical analysis consisted of a description of the variables according to the scale of measurement. For bivariate and multivariate analysis, we used binary logistic regression. We fitted a multivariate model to estimate the strength of association between our dependent variable and the independent variables, which is expressed as odds ratios (OR) with $95 \%$ confidence intervals $(95 \% \mathrm{Cl})$. While we also reported the $p$ values that were considered statistically significant ( $p$ value $<0.05)$, to construct the final model we followed standard guidelines by adding variables that in the bivariate analysis had a statistical significance of $p<0.25$ (Hosmer \& Lemeshow, 2000, Bagley, White, Golomb, 2001). The test variance inflation factor (VIF) was used to analyse, and where appropriate, to avoid multi-collinearity between independent variables. In the final model, we used a specification error test (link test). The test first considered the link function of the outcome variable on the left-hand side of the equation. We chose the logit function (in logistic regression) as the correct function to use. Second, on the righthand side of the equation, we assumed that we had parsimoniously included all relevant variables. The logit function is a linear combination of the predictors. After fixing the main effects, interactions were tested; none proved to be significant at $p<0.15$. We finally characterized the overall fit of the model per standard recommendations (Hosmer \& Lemeshow, 2000; Bagley, White, Golomb, 2001). All analysis used Stata $11.0 \circledast$.

\section{Ethical approval}


167 All procedures performed on human participants were in accordance with the ethical 168 standards of the institutional and/or national research committees, and with the 1964

169 Helsinki declaration, its later amendments, or comparable ethical standards. The

170 approval reference / number from the Institutional Ethical Review Committee of the

171 UAEH: 34-2009-RAZONES EXTRACCIONES-CEMS-11. Formal approval was granted

172 by the institutional ethical review committee of the UAEH. Data collected were

173 anonymized from the patient's charts.

\section{Results}

177 A total of 749 teeth were extracted in 331 patients aged 18 and older during the study

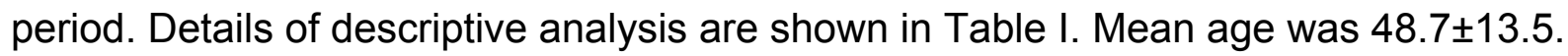
Most extractions were performed on women $(n=487 ; 65.0 \%)$. There were $418(55.8 \%)$ extractions performed in the maxilla, and most were posterior teeth $(n=484 ; 64.6 \%)$; specifically, molars accounted for $44.0 \%(n=330)$. The results show that 161 teeth

$182(21.5 \%)$ were extracted for prosthetic reasons.

The results of the bivariate analysis (Table II) were taken into account for the construction of the multivariate logistic regression model in Table III. It showed that as age increased, the likelihood of having an extraction driven by prosthetic treatment planning increased $3 \%(O R=1.03, p<0.001)$. Women $(O R=1.57, p<0.05)$ were more

187 likely to have a dental extraction for such reasons. Molars $(O R=2.70, p<0.001)$ were the teeth most likely to be extracted as part of a pre-prosthetic treatment plan. As the total 
189 number of extractions per patient increased, the chance of having them done for

190 prosthetic reasons decreased $(\mathrm{OR}=0.94, \mathrm{p}<0.05)$.

191

192

193

194

195

196

197

198

199

200

201

202

203

204

205

206

207

208

209

210

211

\section{Discussion}

The study in a dental school clinic situated in an emerging economy country such as Mexico showed that one fifth $(21.5 \%)$ of teeth were extracted because of prosthetic indications. This is a considerable proportion of the teeth extracted overall. Our figures are similar to those found in other studies; we annotate here the findings relevant to countries broadly in the same level of economic development and/or similar availability of dental care services. For example, Abreu et al. (1998) found that prosthetic treatment planning extractions accounted for $23.2 \%$ of all extractions performed in a dental school clinic in Minas Gerais, Brazil. Similarly, Kalauz, Prpić-Mehičić \& Katanec (2009) conducted a study in a dental school clinic in Zagreb (Croatia) and found that the prevalence of prosthetic extractions was $18.7 \%$, while Alomari, Khalaf \& Al-Shawaf (2013) reported the proportion of teeth extracted for prosthetic indications was $15.9 \%$ in Kuwait University. However, other authors have reported different results; Jafarian \& Etebarian (2013) described a frequency of $4.1 \%$ in an Iranian study, while Rubiños et al. (2008) in Spain showed the rate was 3.4\% in publicly funded clinical services. These variations may be partly attributed to diverse methodological approaches, to different settings included (dental school clinics, hospitals, or dental offices), and/or to various response rates, as well as wide variation in ages of the populations sampled (Jafarian \& Etebarian, 2013). Tooth extraction should ideally be the last resort alternative among 
212 dental treatment options, and clinicians should be careful in deciding whether a tooth -

213 especially a healthy tooth - should ever be removed. In making this decision, the

214 clinician needs information such as tooth type or the prosthetic plan intended. Ethical

215 implications apply, as the best interest of the patient ought to be driving the decision to

216 undertake an extraction for prosthetic reasons; in this context, prevalence of extractions,

217 their reasons, and associated factors ought to be available to clinicians. Moreover,

218 candid discussion of such scenario and factors during dental training may strengthen

219 the dental education curriculum. Specifically, age appears important as Jafarian \&

220 Etebarian (2013) in Iran, Abreu et al. (1998) in Brazil, and Rubiños et al. (2008) in Spain

221 reported that in older people, extractions for prosthetic reasons increased in relation to

222 age. Unlike the findings in our study, Jafarian \& Etebarian (2013) observed that

223 prosthetic reasons for extractions were more common among men. That Iranian study

224 also reported that posterior teeth were extracted more frequently for prosthetic reasons

225 than anterior teeth (Jafarian \& Etebarian, 2013). But Abreu et al. (1998) in Brazil, Kalauz

226 et al. (2009) in Croatia, and Alomari, Khalaf \& Al-Shawaf (2013) in Kuwait noted that

227 anterior teeth were preferentially extracted for prosthetic purposes.

228 There are no unequivocal guidelines for prosthetic extractions, and even less clinical

229 guidelines that may be considered appropriate to cut across the enormous assortment

230 of clinical practices, evidence based indications, or costing/reimbursement models for

231 clinical care in the highly diverse locations across the most developed to the least

232 developed countries. There is considerable scope to inform clinical practices through

233 future research. 
234 There are some limitations to the present study that should be considered when

235 interpreting the data, in particular when attempting to apply its message to other

236 contexts. For example, the information was obtained from patients who sought care in

237 dental school clinics; it may therefore be not representative of dental offices or other

238 service outlets in Mexico. Adding strength to our design, however, is the fact that faculty

239 helping students in planning and undertaking prosthetic treatment led to a measure of

240 criteria standardization. This feature may not be available outside dental school clinics.

241 This is an important consideration, as Kassebaum et al. (2014b) noted that tooth loss

242 reflects underlying dental disease as well as patients' and dentists' attitudes, the dentist-

243 patient relationship, the availability and accessibility of dental services, and the

244 prevailing philosophies of dental care. It is crucial to keep in mind that our data pertains

245 directly only to one clinical care outlet; however important may be the care afforded to

246 the open public through dental school clinics in Mexico, it is a domain without

247 systematic data collection or evaluation. Market share, clinical impact, and public health

248 significance are poorly understood - just as they are in many similar environments in

249 either industrialized, emerging, and less-developed countries.

\section{Conclusion}

A significant amount (21.5\%) of the extractions of permanent teeth were performed as part of a prosthetic treatment plan in an open population of Mexican adults seeking care at a dental school clinic. Age, sex, type of tooth, and total number of extractions moderated such pattern. Overall prevalence of tooth extractions should be considered 
257 in light of these results, to place in context the various reasons why some teeth are

258 ultimately lost and not simply attribute all tooth loss to clinical neglect or barriers in

259 access to care. While extracting a tooth is generally considered to be the last alternative

260 in dental treatment options, the influence of factors such as age, the type of tooth, or

261 specific prosthetic indications must also be considered.

262 
263

264

265

266

267

268

269

270

271

272

273

274

275

276

277

278

279

280

281

282

283

284

\section{References}

Abreu MHNG, Drummond SN, Pordeus IA, Paixão HH. 1998. Correction factor for the M-component in the DMFS index in an adult brazilian population. Revista de Odontologia da Universidade de São Paulo 12:323-8.

Alomari QD, Khalaf ME, AI-Shawaf NM. 2013. Relative contribution of restorative treatment to tooth extraction in a teaching institution. Journal of Oral Rehabilitation 40:464-71.

Armitage GC, Research, Science and Therapy Committee of the American Academy of Periodontology. 2003. Diagnosis of periodontal diseases. Journal of Periodontology 74:1237-47.

Bagley SC, White H, Golomb BA. 2001. Logistic regression in the medical literature: Standards for use and reporting, with particular attention to one medical domain. J Clin Epidemiol 54:979-85.

Davarpanah M, Jansen CE, Vidjak FM, Etienne D, Kebir M,Martinez H. 1998. Restorative and periodontal considerations of short clinical crowns. International Journal of Periodontics and Restorative Dentistry 18: 425-33.

Freitas-Júnior AC, Silva AM. 2012. Pre-prosthetic orthodontic treatment using personalized elastic separators for optimization of emergence profile in esthetic crowns: a clinical report. Journal of Prosthodontics 21:52-55.

Greenwell H, Committee on Research, Science and Therapy. American Academy of Periodontology. 2001. Position paper: Guidelines for periodontal therapy. Journal of Periodontology 72:1624-8. 
285 Haseeb M, Ali K, Munir MF. 2012. Causes of tooth extraction at a tertiary care centre 286 in Pakistan. Journal of Pakistan Medical Association 62:812-5.

287 Hobdell M, Petersen PE, Clarkson J, Johnson N. 2003. Global goals for oral health 288 2020. International Dental Journal 53:285-8.

Hosmer DW, Lemeshow S. 2000. Applied logistic regression. 2da ed. Jonh Wiley \& Sons Interscience Publication; New York.

Jafarian M, Etebarian A. 2013. Reasons for extraction of permanent teeth in general dental practices in Tehran, Iran. Medical Principles and Practice 22:239-44.

Kalauz A, Prpić-Mehičić G, Katanec D. 2009. The Reasons for Tooth Extractions: A Pilot Study. Acta Stomatologica Croatica 43:110-6.

Kassebaum NJ, Bernabé E, Dahiya M, Bhandari B, Murray CJ, Marcenes W. 2014. meta-regression. Journal of Dental Research 93:1045-53.

Kassebaum NJ, Bernabé E, Dahiya M, Bhandari B, Murray CJ, Marcenes W. 2014b. Global Burden of Severe Tooth Loss: A Systematic Review and Metaanalysis. Journal of Dental Research 93(7 Suppl):20S-28S.

Kassebaum NJ, Bernabé E, Dahiya M, Bhandari B, Murray CJ, Marcenes W. 2015. Global burden of untreated caries: a systematic review and metaregression. Journal of Dental Research 94:650-8.

Lee CY, Chang YY, Shieh TY, Chang CS. 2015. Reasons for permanent tooth extractions in Taiwan. Asia Pacific Journal of Public Health 27:NP2350-7.

Lesolang RR, Motloba DP, Lalloo R. 2009. Patterns and reasons for tooth extraction at the Winterveldt Clinic: 1998-2002. South African Dental Journal 64:214-5. 
308 Marcenes W, Kassebaum NJ, Bernabé E, Flaxman A, Naghavi M, Lopez A, Murray CJ. 2014. Global burden of oral conditions in 1990-2010: a systematic analysis. Journal of Dental Research 92:592-7.

311 Medina-Solís CE, Mendoza-Rodríguez M, Márquez-Rodríguez S, De la Rosa-

Santillana R, Islas-Zarazua R, Navarrete-Hernández JD, Maupomé G. 2014 Reasons why erupted third molars are extracted in a public university in Mexico. West Indian Medical Journal 63:354-8.

Medina-Solís CE, Pontigo-Loyola AP, Pérez-Campos E, Hernández-Cruz P, De la Rosa-Santillana R, Navarete-Hernández JJ, Maupomé G. 2013. [Principal reasons for extraction of permanent tooth in a sample of Mexicans adults]. Revista de Investigación Clínica 65:141-9.

Minaya-Sánchez M, Medina-Solís CE, Casanova-Rosado JF, Vallejos-Sánchez AA, Casanova-Rosado AJ, Mendoza-Rodríguez M, Márquez-Corona ML, Maupomé G. 2015. Prevalence of functional dentition in a group of Mexican male adults. Working paper. Autonomous University of Campeche. Mexico.

Pérez-Núñez R, Medina-Solis CE, Maupomé G, Vargas-Palacios A. 2006. Factors associated with dental health care coverage in Mexico: Findings from the National Performance Evaluation Survey 2002-2003. Community Dentistry and Oral Epidemiology 34:387-97.

Rubiños-López E, Rodríguez-Vázquez LM, Varela-Centelles A, Varela-Centelles P. 2008. [Causes of tooth extraction recorded in the galician health service]. Atencion Primaria 40:157-8. 
330 Saheeb BD, Sede MA. 2013. Reasons and pattern of tooth mortality in a Nigerian

331 Urban teaching hospital. Annals of African Medicine 12:110-4.

332 


\section{Table 1 (on next page)}

Descriptive analysis of independent variables included. 
1 Table 1. Descriptive analysis of independent variables included.

2

\begin{tabular}{|l|l|}
\hline Variable & Mean \pm sd \\
\hline Age & $48.70 \pm 13.54$ \\
\hline Extracted teeth & $4.25 \pm 3.63$ \\
\hline & $\begin{array}{l}\text { Frequency } \\
(\%)\end{array}$ \\
\hline $\begin{array}{l}\text { Sex } \\
\text { Men } \\
\text { Women }\end{array}$ & $262(35.0)$ \\
\hline $\begin{array}{c}\text { Arch } \\
\text { Upper } \\
\text { Lower }\end{array}$ & $487(65.0)$ \\
\hline $\begin{array}{l}\text { Sextant } \\
\text { Anterior } \\
\text { Posterior }\end{array}$ & $265(53.8)$ \\
\hline $\begin{array}{l}\text { Tooth type } \\
\text { incisors } \\
\text { canines } \\
\text { premolars } \\
\text { molars }\end{array}$ & $484(64.6)$ \\
\hline
\end{tabular}

3

$4 \quad$ * Number of extractions undertaken per patient. 


\section{Table 2 (on next page)}

Bivariate analysis between prosthetic extractions and independent variables. 
1 Table 2. Bivariate analysis between prosthetic extractions and independent variables.

2

\begin{tabular}{|c|c|c|c|c|}
\hline & Others & Prosthetic & OR $(95 \% \mathrm{Cl})$ & $\begin{array}{l}\mathrm{p} \\
\text { value }\end{array}$ \\
\hline Age & $48.31 \pm 13.91$ & $50.14 \pm 11.98$ & $\begin{array}{l}1.01(1.00- \\
1.02)\end{array}$ & 0.128 \\
\hline Extracted teeth & $4.41 \pm 3.79$ & $3.66 \pm 2.90$ & $\begin{array}{l}0.94(0.89- \\
0.99)\end{array}$ & 0.021 \\
\hline $\begin{array}{l}\text { Sex } \\
\text { Men } \\
\text { Women }\end{array}$ & $\begin{array}{l}218(83.2) \\
370(76.0)\end{array}$ & $\begin{array}{l}44(16.8) \\
117(24.0)\end{array}$ & $\begin{array}{l}1^{*} \\
1.57(1.07- \\
2.30)\end{array}$ & 0.022 \\
\hline $\begin{array}{l}\text { Arch } \\
\text { Upper } \\
\text { Lower }\end{array}$ & $\begin{array}{l}335(80.1) \\
253(76.4)\end{array}$ & $\begin{array}{l}83(19.9) \\
78(23.6)\end{array}$ & $\begin{array}{l}1^{*} \\
1.24(0.88- \\
1.76)\end{array}$ & 0.220 \\
\hline $\begin{array}{l}\text { Sextant } \\
\text { Anterior } \\
\text { Posterior }\end{array}$ & $\begin{array}{l}223(84.2) \\
365(75.4)\end{array}$ & $\begin{array}{l}42(15.8) \\
119(24.6)\end{array}$ & $\begin{array}{l}1^{*} \\
1.73(1.17- \\
2.55)\end{array}$ & 0.006 \\
\hline $\begin{array}{l}\text { Tooth type } \\
\text { incisors } \\
\text { canines } \\
\text { premolars } \\
\text { molars }\end{array}$ & $\begin{array}{l}156(86.2) \\
67(79.8) \\
131(85.1) \\
234(70.9)\end{array}$ & $\begin{array}{l}25(13.8) \\
17(20.2) \\
23(14.9) \\
96(29.1)\end{array}$ & $\begin{array}{l}1^{*} \\
1.58(0.80- \\
3.12) \\
1.09(0.59- \\
2.02) \\
2.56(1.58- \\
4.16)\end{array}$ & $\begin{array}{l}0.185 \\
0.770 \\
0.000\end{array}$ \\
\hline
\end{tabular}

3

$4 \quad{ }^{*}$ Reference category. 


\section{Table 3 (on next page)}

Multivariate model of logistic regression between prosthetic extractions and independent variables. 
1 Table 3. Multivariate model of logistic regression between prosthetic extractions and 2 independent variables.

3

\begin{tabular}{|l|l|l|}
\hline & OR $(95 \% \mathrm{Cl})$ & $\begin{array}{l}\mathrm{p} \\
\text { value }\end{array}$ \\
\hline Age & $\begin{array}{l}1.03(1.02- \\
1.05)\end{array}$ & 0.000 \\
\hline Extracted teeth & $\begin{array}{l}0.94(0.88- \\
0.99)\end{array}$ & 0.027 \\
\hline $\begin{array}{l}\text { Sex } \\
\text { Men }\end{array}$ & $1^{*}$ & \\
Women & $1.57(1.05-$ & 0.027 \\
\hline $\begin{array}{l}\text { Tooth type } \\
\text { incisors/canines } \\
\text { premolars } \\
\text { molars }\end{array}$ & $1^{*}$ & \\
& $1.00(0.57-$ & 0.993 \\
& $1.76)$ & 0.000 \\
& $2.70(1.72-$ & \\
$4.22)$ & \\
\hline
\end{tabular}

4

$5 \quad$ * Reference category.

6 Goodness of fit test: Hosmer-Lemeshow $\operatorname{chi}^{2}(8)=10.00, p=0.2651$.

7 Linktest (specification error test): predictor $=0.030$; predictor $^{2}=0.648$. 